\title{
3. Fertility and the demography of Indigenous Australians: What can the NATSISS 2008 tell us?
}

\author{
Kim Johnstone and Ann Evans
}

The primary concerns of demographers relate to population size, distribution and composition - how big the population is; the rate of population growth; the population's age and gender profiles; and where people are located. There are three components that drive population size and composition changes (or stasis) over time:

- fertility: the number of live births within a population, with a particular interest in the age women have babies and how many they have over their life time

- mortality: not only how many people die, but also what age they die, and

- migration: where are people moving to and from, how long are they moving for, how old are they when they move (Swanson and Siegel 2004).

To understand the demography of Indigenous Australians these are fundamental components that require investigation, and this necessitates counts of people, births and deaths by the Indigenous status of individuals. In Australia our statistical systems remain less than reliable in terms of providing us with population data for the Indigenous population (Johnstone 2009; Taylor 2009). Indeed, Len Smith described Australia's inability to reliably measure Indigenous life expectancy 'a frank failure of the statistical system' (Smith, Barnes and Choi 2008). This paucity of good quality data for Australia's Indigenous population means specialised data systems such as the National Aboriginal and Torres Strait Islander Social Survey (NATSISS) are particularly welcomed. As Taylor (2009: 119) noted in relation to research on Indigenous demography:

The unfolding National Aboriginal and Torres Strait Islander Social Survey program conducted by the Australian Bureau of Statistics (ABS) also now provides an improved basis for establishing proximate determinants (the drivers of fertility change).

This opportunity has not been realised, as the NATSISS 2008 provides very little insight into the demography of Indigenous Australians because the data relating to most demographic processes and events are simply unavailable. This chapter argues that the absence of questions relating to Indigenous demography per se from the NATSISS 2008, particularly fertility, represents a lost opportunity. 
It outlines what is known about Indigenous demography in Australia, with a particular focus on fertility. Using fertility as a case study, the paper looks at what data are available from other sources and highlights Australia's knowledge gaps based on these data. The chaper closes by exploring what knowledge could have been gained by the inclusion of fertility questions in the NATSISS and discusses the policy implications of properly understanding the fertility drivers of population change.

\section{Demography of Indigenous Australians: What do we know?}

Mortality, particularly life expectancy at birth, has been the headline population indicator for Australian Government 'closing the gap' policies with Indigenous populations experiencing higher death rates at all ages compared to nonIndigenous Australians (ABS 2009). The difficulties associated with reporting changes to Indigenous life expectancy at birth has led to a reassessment of the method used to calculate life expectancy (ABS 2008a) and work is underway to improve the counting of Indigenous deaths (for example, through data linkage projects such as SA-NT DataLink). Even with improved counting of Indigenous deaths, however, there remain issues in understanding population mortality measures, particularly over time, because of changing population counts in the census that affect denominator populations (Cunningham 1998).

As Taylor and Bell (Chapter 2, this volume) have shown, analysis of Indigenous population movements is limited by data sources failing to link population movements to contingent events. That said, a higher than average migration rate is apparent - with median duration for residence in a house of less than four years. There is a higher probability of moving house among Indigenous people who are renting or unemployed, although living remotely reduces the propensity to move. There is decidedly more uncertainty around the measurement of shortterm, circular mobility (Morphy 2010; Prout 2008) and there is remarkably little known about how population mobility might affect population data collection processes (Johnstone 2011; Zhao et al. 2009).

Fertility levels among Indigenous women in Australia are not high, with total fertility rates (TFRs) of less than three births per woman (ABS 2010). The stand out characteristic of Indigenous fertility is the young age that women have children. Fig. 3.1 shows that over the 10-year period for which fertility data by Indigenous status are available nationally, the number of babies born to Indigenous women (TFR) was relatively stable to 2007 when it started rising. This pattern of rising fertility from 2007 is also seen in the teenage fertility rates, which are exceptionally high (Fig. 3.2). 
Fig. 3.1 Total fertility rates, Indigenous and total populations, Australia, 1998-2009

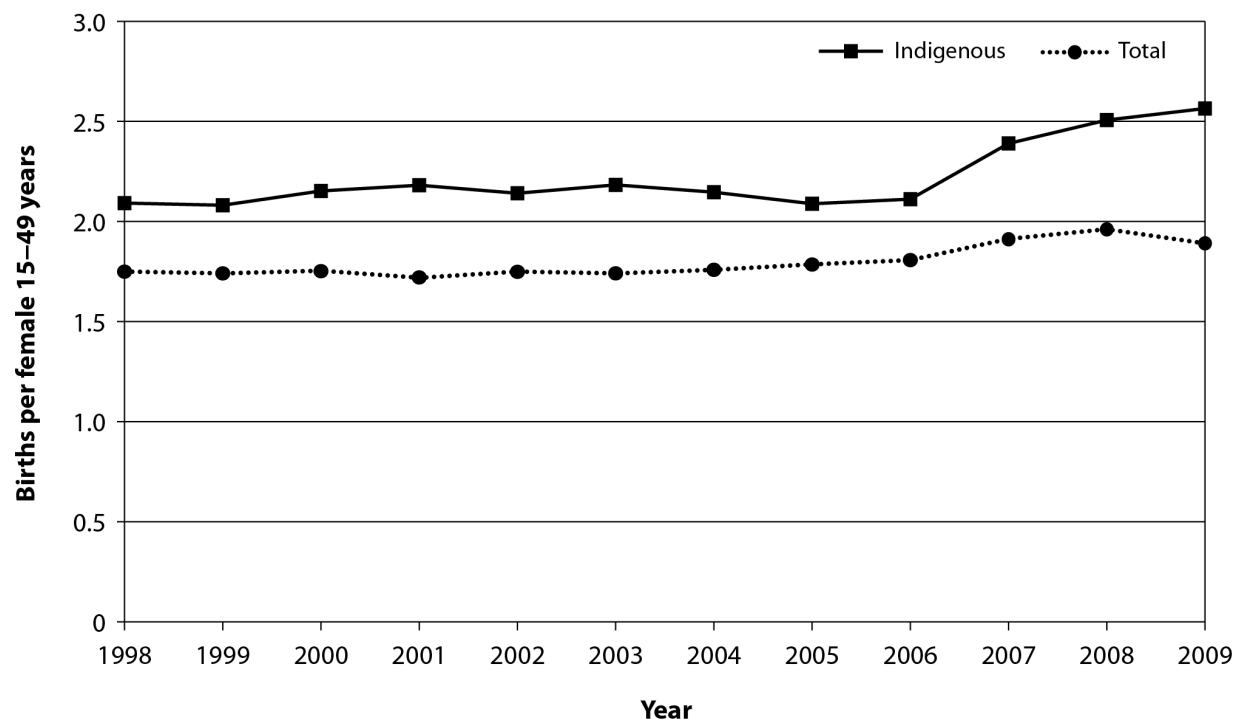

Source: ABS 2010

Fig. 3.2 Teenage fertility rates, Indigenous and total populations, Australia, 1998-2009

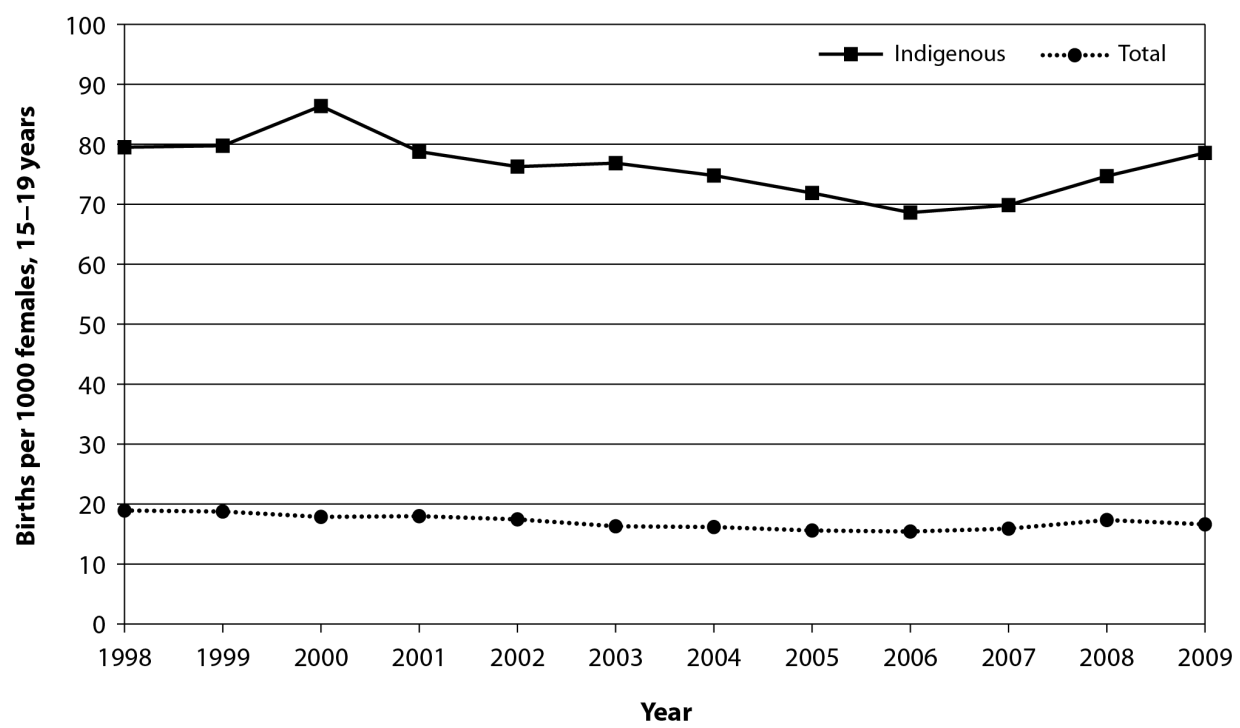


Despite indications of rising fertility in recent years among Indigenous women in Australia, any apparent trends must be viewed with caution. There are significant caveats on the data because of ever improving collection of birth registration information by Indigenous status. In 2007 it became a requirement that births had to be registered with the Registrar of Births, Deaths and Marriages in the State or Territory where the birth took place in order for mothers to receive the 'baby bonus', an Australian Government payment to mothers following the live birth of a child (Department of Families, Housing, Community Services and Indigenous Affairs (FaHCSIA) 2009). Some States have experienced notable under-registration of Indigenous births in the past (Gerber 2009a, 2009b; Orenstein 2008) and the 'baby bonus' requirement will have obvious flow on effects for fertility rates based on registrations.

Fertility rates based on vital registration data are also affected by the temporal births data reflecting date of birth registration rather than date of birth. Late registrations are thus important in some jurisdictions where there may be significant delays in processing registration and concentrated efforts to clear a backlog for a short period of time. Efforts to ensure all citizens have a birth certificate can also contribute to late registrations, as happened in Dubbo (New South Wales) in 2008 when school-age children needed a birth certificate to participate in sports activities (ABC News 2008). These data caveats are not insignificant, and the issues with registration differ across State and Territory lines.

Fig. 3.3 Indigenous age-specific and total fertility rates, Australian States and Territories, 2009

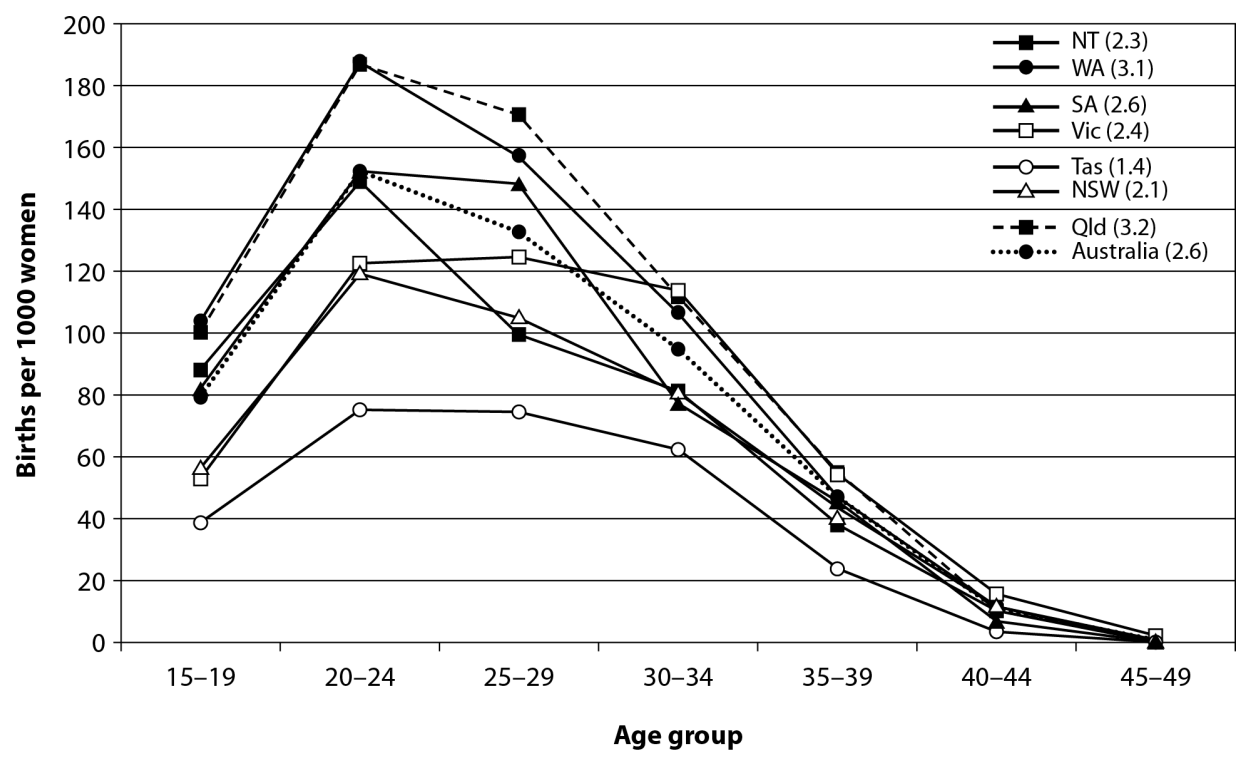


Indigenous age-specific fertility rates across Australia's States and Territories are shown in Fig. 3.3, and in each State and Territory fertility rates are highest among Indigenous women aged 20-24 years. This is notably younger than for Australia as a whole, where fertility is highest in the 30-34 year age group (ABS 2010). There are differences across the States and Territories, with Tasmania having the lowest fertility rates for all age groups. Queensland and Western Australia have the highest fertility, most notably at the youngest ages. This is a recent pattern for these two states, however, as up to 2007 (from the time State/Territory comparisons have been available) the Northern Territory has had the highest fertility among Indigenous women. Northern Territory rates have not risen from 2007 as they have for Queensland and Western Australia and data collection issues are likely influencing trends in these jurisdictions. The Northern Territory rate stands out compared to the other jurisdictions because the peak childbearing at ages 20-24 years is notably higher than at ages 25-29 years, whereas elsewhere the difference is less marked.

These State and Territory differences, and regional investigations of Indigenous fertility patterns (Johnstone 2011; Taylor, Brown and Bell 2006) provide a strong case for looking at fertility by remoteness classifications, particularly across Northern Australia, rather than jurisdictional boundaries. This is where national survey data can be particularly useful because they are not constrained by eight different data collection and processing agencies.

\section{Data sources that help us to understand Indigenous fertility in Australia}

While this paper argues that the NATSISS is an appropriate tool for capturing information about Indigenous fertility, an argument for the preclusion of any demography-related questions can be made if the same data are captured elsewhere. This section outlines other sources of data that are available for analysis of Indigenous fertility in Australia.

Vital registration data (on which the figures for this paper are based) are collected by each jurisdiction's Registrar of Births, Deaths and Marriages, and collated by the ABS. They provide information about Indigenous status of the mother, father and child (fertility rates in this paper are based on births to Indigenous mothers only). Other information includes age of parents, place of usual residence, occupation, and country of birth of parents. From 2007, data on parity (or the number of children ever born to the mother) for all previous births has been collected. As already noted, there are issues with completeness of registration for Indigenous births across different jurisdictions and delayed registration. Vital registration data are generally available by year of registration 
rather than year of the baby's birth, which can affect trend analysis. There are also issues of numerator and denominator mismatch, particularly going back in time with population (denominator) undercounts being greater the further back in time you go (Johnstone 2009).

The other main source of births data is the perinatal data collection, which is collated nationally from State/Territory collections. The perinatal data set records the Indigenous status of the mother, her age, and usual place of residence alongside a range of information about pregnancy and birth by the year the birth took place. Variables available in this data set include number of antenatal visits, type of birth, birthweight, number of post-natal days in hospital, and so forth (Leeds et al. 2007). For the demographer, one of the most important aspects relates to parity information, which enables investigation of the timing and spacing of births, and in particular, changes to these over time. In some States, the perinatal data provide a more accurate count of births than the vital registration data (Parr, Culpin and Wilson 2008) but there are issues with accuracy of identification of Indigenous status in some States (Robertson, Lumley and Berg 1995). It is also important to be mindful that the differences between the perinatal and vital registration data sets can result in different trends if longitudinal analysis is carried out (Johnstone 2010). As ever, there are also issues of numerator and denominator mismatch. Children identified as Indigenous may have a mother who is not Indigenous. Therefore, calculating Indigenous fertility rates results in some children being included in the numerator whose mother is not included in the denominator.

Prior to the inclusion of an Indigenous identifier in the vital registration and perinatal data sets, the quinquennial census was the primary source of information about Indigenous fertility in Australia (Gray 1983). The most important question for fertility analysis asks women aged 15 years of age and older how many children they have ever had born alive. This question was asked prior to 1986 but it only elicited information about number of children ever-born from ever-married women or currently married women, and not asked of Indigenous women for inclusion in the national census counts prior to 1971. A notable advantage of the census for fertility analysis is that the problem of matching numerators and denominators is avoided.

The census data cannot be used uncritically, however, because of undercount and non-response. In 2006, for example, the 2006 post-enumeration survey showed the Indigenous population was undercounted by 11.5 per cent across Australia (ABS 2007). Of women who answered the question about the number of children they have ever born alive, 5 per cent did not provide a response to the Indigenous status question. Of the women older than 15 years of age who did identify as Indigenous, 8 per cent did not answer the question on how many children they had ever had (ABS 2008b). Moreover, observations of census data 
collection in remote Indigenous communities found that often only currently living children were counted when census forms were filled in (Morphy et al. 2007). These factors combine to make fertility analysis based on the census indicative at best.

National estimates of Indigenous fertility have also been derived from a question included in NATSISS 1994 and NATSISS 2002, asking women for the number of children they have ever had born alive (Kinfu 2005). The utility of these earlier NATSISS data is their inclusion in a questionnaire that captured a range of data that allowed exploration of influences on fertility outcomes, in particular questions relating to cultural participation and cultural identification and health status. One of the shortcomings of the NATSISS data for fertility analysis is that at the sub-national level the numbers are too small in the sample to enable access to data for multi-variate analysis (Johnstone 2011). Another issue has been the lack of use made of the children ever born question from the 1994 or 2002 NATSISS data - there have simply been too few demographers who have been able to prioritise the work.

\section{Indigenous fertility in Australia: Knowledge gaps}

While the data sources detailed in the previous section indicate relatively rich sources of data, they are inadequate for answering some key questions about Indigenous fertility in Australia. Primary among these, are questions about future fertility trends for Indigenous women. Following dramatic fertility declines in the 1960s and 1970s among Indigenous Australians it was assumed these fertility declines would continue and that Indigenous women would defer childbearing from young to older ages (Gray 1983, 1990). Quite simply, these expected fertility declines have not eventuated. While there is some evidence of deferred childbearing, it is not of the same magnitude of the patterns seen among the non-Indigenous population (Johnstone 2011). There is not enough information to make an informed estimate of what future trends will look like.

There are significant knowledge gaps surrounding Indigenous fertility differences across rural-remote and urban parts of Australia. International and historical fertility patterns across diverse populations have shown lower fertility in cities compared to rural areas (Carmichael and McDonald 2003; Pool 1991) and it is assumed the same holds true for Indigenous Australians. The work of Taylor, Brown and Bell (2006) point to regional fertility differences for the Indigenous population outside the populous eastern seaboard, with higher fertility in the savanna regions compared to arid zones. Research by Johnstone $(2010,2011)$ in the Northern Territory points to an emerging trend of higher Indigenous fertility in urban settings compared to rural and remote regions. 
The data to ascertain if this trend is an artefact of data collection systems or attributable to other factors such as contraception, health status, or family commitments are unavailable.

Remarkably little is also known about the factors that influence when Indigenous women have children. The timing of childbearing is very important in order to understand population dynamics (e.g. population ageing, dependency ratios). The research that has been done shows that Indigenous women who are employed, who finished high school or who have post-secondary qualifications have less children (albeit not by large margins) and tend to start childbearing later (again, not by long periods) (Gray 1989; Johnstone 2011; Khalidi 1989). Very little is known, however, about the sequence of timing for children, education and employment among Indigenous women. We don't know what will influence Indigenous women's decisions to have children at a particular age. Young childbearing could reflect a high level of family support available to mothers, a lack of other options for young women, lack of access to contraception, a high rate of sexual assault, or deliberate entry to the 'age grades' of adulthood by becoming a mother. All are plausible and supported by small, qualitative studies but none are able to be substantiated at the population level and lead to conclusions about what may happen in the future.

In a similar vein, nothing is known about the factors influencing how many children Indigenous women will have. There is a huge knowledge gap around how many children Indigenous women want to have or how many they will have. It is simply impossible to determine if the relatively low TFR reflects Indigenous women's wanted family size, or whether it is the impact of secondary infertility. The high recorded levels of sexually transmitted infections and health issues that we know affect fertility (e.g. diabetes, smoking) means Indigenous women might be having fewer children than they want.

Understanding these fertility issues is important in order to understand what is happening with the Indigenous population and to establish some reasonable parameters for what will happen into the future. This is essential for planning what services and infrastructure are needed for the birth cohorts being born to Indigenous mothers (see Fig. 3.4). Despite a relatively stable TFR, the number of Indigenous babies being born each year continues to grow (and Fig. 3.4 excludes Indigenous babies born to non-Indigenous mothers). There are implications for housing - among a population for whom overcrowding is well recognised as a problem, for schools, for health services, and so forth. More importantly, there is great uncertainty about what these birth cohorts of babies born to Indigenous mothers will do when they themselves reach childbearing ages. 
Fig. 3.4 Total fertility rates and cohort size, births to Indigenous women in Australia, 1998-2010

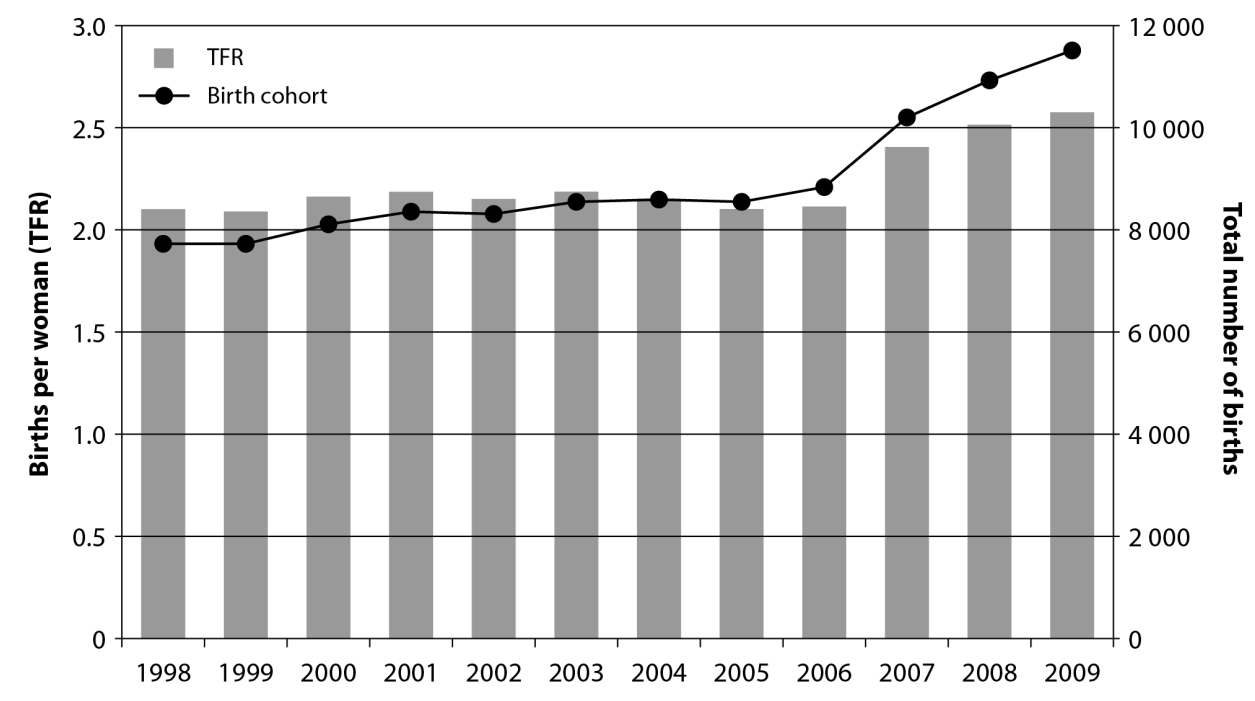

Source: ABS 2010

Understanding the age structure of fertility is critical for the implementation of social policy. In the area of education and employment, for example, any success in 'closing the gap' when women are having babies at a young age will necessitate the provision of child care so women can attend school or go to work. There are health implications for young mothers having babies, and also for the children of those young mothers, as well as socioeconomic impacts (Bradbury 2006; Hendrickson 1998; Jeon, Kalb and Vu 2008; Murphy and Carr 2007).

If the fundamentals of population size and structure are unclear there will always be questions of doubt about the validity of other research that requires a population denominator. It is not just demography, but most social science and epidemiological research that suffer from a less than complete knowledge about Indigenous populations.

\section{Including fertility in the NATSISS}

While the NATSISS itself cannot be a catch-all solution to answering these questions about what will happen with Indigenous fertility into the future, its role as a national survey specifically targeting Aboriginal and Torres Strait Islander peoples means it is uniquely placed to help better understand Indigenous population dynamics. In the first instance, including a fertility question in the NATSISS would provide another data source with which to compare the routine 
data collections. There are important questions about whether all births to Indigenous women are counted in the vital registration and perinatal data sets, and any data source that allows a check and balance is useful. Even for those correlations that are collected in the census such as age, education, employment and income, the NATSISS provides a more reliable source of information because of the way the questions are asked and information elicited from respondents. There are different introductory questions and explanations, and data collection mechanisms that mean the NATSISS results are probably more complete than census data.

The NATSISS 2008 provides its own important clues as to the importance of understanding Indigenous fertility better. Nearly 1 in 10 respondents to the NATSISS 2008 identified pregnancy as a stressor (9\%); 2 per cent of the sample found pregnancy a personal stressor. (Unfortunately we can't use these data as a fertility proxy because there would have been people surveyed who experienced pregnancy but were not stressed, or did not view the pregnancy of a friend or family member as a stressor.) That so many respondents found pregnancy to be stressful indicates that it is an area about which more needs to be known.

Because of the NATSISS survey structure, it could provide important information about the timing and spacing of Indigenous childbearing if it included questions about mother's age at the birth of each child. The NATSISS could also include questions about future children, childbearing intentions and ideal family size. In order to understand if education and employment affect family size, and how they might do so, questions about women's education levels and employment status at the time each child was born are important. At the very least, including education and employment status for a woman's first birth provides important clues to the timing of these events.

Ultimately, including a question on parity in future NATSISS would enable investigation of fertility estimates alongside important proximate determinants that are unable to be explored from census data alone. One of the missed opportunities for NATSISS 2008 is an inability to look at the results from a new question on length of time in the workforce alongside number of children ever born. The NATSISS questions on cultural participation and cultural identification, despite their constraints, also provide an opportunity to look at what factors beyond socioeconomic correlates might influence fertility decisions. Other correlates that would have been useful to look at alongside the children ever born question include childcare used, health status, neighbourhood problems, and discrimination.

There is an overwhelming need to better understand Indigenous fertility and the exclusion of the children ever born question from the NATSISS 2008 represents a lost opportunity. If in the future questions about fertility are to be included 
in the NATSISS, these should focus on timing and spacing of childbearing and try to gather information that might help explain influences on childbearing outcomes.

\section{References}

ABC News 2008. 'Birth certificate scheme targets Dubbo indigenous population', viewed 29 September 2011, available at <http://www.abc.net.au/news/ stories/2008/03/12/2187060.htm>

Australian Bureau of Statistics (ABS) 2007. Population Distribution, Aboriginal and Torres Strait Islander Australians, cat. no. 4705.0, ABS, Canberra.

2008a. Discussion Paper: Assessment of Methods for Developing Life Tables for Aboriginal and Torres Strait Islander Australians, cat. no. 3238.0.55.002, ABS, Canberra.

2008b. Population Characteristics, Aboriginal and Torres Strait Islander Australians, 2006, cat. no. 4713.0, ABS, Canberra.

2009. 2008 Deaths Australia, cat. no. 3302.0, ABS, Canberra.

2010. Births Australia 2009, cat. no. 3301.0, ABS, Canberra.

Bradbury, B. 2006. 'Disadvantage among Australian young mothers', Australian Journal of Labour Economics, 9 (2): 147-71.

Carmichael, G. A. and McDonald, P. 2003. 'Fertility trends and differentials', in S. Khoo and P. McDonald (eds), The Transformation of Australia's Population 1970-2030, UNSW Press, Sydney.

Cunningham, J. 1998. 'Implications of changing Indigenous populations estimates for monitoring health trends', Australasian Epidemiologist, 5 (1): 6-8.

Department of Families, Housing, Community Services and Indigenous Affairs (FaHCSIA) 2009. 'Baby Bonus - introducing birth registration as a condition, viewed 29 March 2011, available from < http://www.fahcsia.gov.au/about/ publicationsarticles/corp/BudgetPAES/budget2007-08/budget2007-07_ wnwd/Pages/Budget2007-07_wnwd-07.aspx>

Gerber, P. 2009a. 'Making visible the problem of invisibility', Law Institute Journal, 83 (10): 52-5. 
2009b. 'Making Indigenous Australians "disappear". Problems arising from our birth registration systems', Alternative Law Journal, 34 (3): 158-67.

Gray, A. 1983. Australian Aboriginal Fertility in Decline, PhD Thesis, ANU, Canberra.

1989. 'Aboriginal fertility: Trends and prospects', NCEPH Working Paper No. 6, National Centre for Epidemiology and Population Health, ANU, Canberra.

1990. 'Aboriginal fertility: Trends and prospects', Journal of the Australian Population Association, 17 (1): 57-77.

Hendrickson, J. 1998. 'The risk of teen mothers having low birth weight babies: Implications of recent medical research for school health personnel', Journal of School Health, 68 (7), 271-75.

Jeon, S., Kalb, G. and Vu, H. 2008. 'The dynamics of welfare participation among women who experienced teenage motherhood in Australia', Working Paper No. 22/08, Melbourne Institute of Applied Economic and Social Research, University of Melbourne, Melbourne.

Johnstone, K. 2009. 'Indigenous fertility rates - how reliable are they?, People and Place, 17 (4): 29-39.

2010. 'Indigenous fertility in the Northern Territory of Australia - what do we know? (what can we know?)', Journal of Population Research, 27 (3): 169-92.

2011. Indigenous Fertility in the Northern Territory of Australia: Stalled Demographic Transition?, PhD Thesis, ANU, Canberra, viewed 3 July 2012, available at <http://hdl.handle.net/1885/8742>

Khalidi, N. A. 1989. 'Aboriginal fertility in Central Australia', NCEPH Working Paper No. 8, National Centre for Epidemiology and Population Health, ANU, Canberra.

Kinfu, Y. 2005. 'Aboriginal child mortality in Australia: Recent levels and covariates', in B. H. Hunter (ed.), Assessing The Evidence on Indigenous Socioeconomic Outcomes: A Focus on the 2002 NATSISS, CAEPR Research Monograph No. 26, ANU E Press, Canberra.

Leeds, K., Gourley, M., Laws, P., Zhang, J., Al-Yaman, F. and Sullivan, E. A. 2007. Indigenous Mothers and Their Babies, Australia 2001-2004, AIHW cat. no. PER 38, Periantal Statistics Series no. 19, AIHW, Canberra. 
Morphy, F. 2010. '(Im)mobility: Regional population structures in Aboriginal Australia', Australian Journal of Social Issues, 45 (3): 363-82.

, Sanders, W., Taylor, J. and Thorburn, K. 2007. 'Appendix B: Commentary on the 2006 Interviewer Household Form', in F. Morphy (ed.), Agency, Contingency and Census Process: Observations of the 2006 Indigenous Enumeration Strategy in Remote Aboriginal Australia, CAEPR Research Monograph No. 28, CAEPR, ANU, Canberra.

Murphy, E. and Carr, D. 2007. Powerful Partners. Adolescent Girls' Education and Delayed Childbearing, Population Reference Bureau, Washington, DC.

Orenstein, J. 2008. 'The difficulties faced by Aboriginal Victorians in obtaining identification', Indigenous Law Bulletin, 7 (8): 14-17.

Parr, A., Culpin, A. and Wilson, T. 2008. 'Estimating and projecting NSW fertility', Paper presented to the Australian Population Association 14th Biennial Conference 2008, Alice Springs.

Pool, I. 1991. Te Iwi Maori. A New Zealand Population Past, Present \& Projected, Auckland University Press, Auckland.

Prout, S. 2008. 'On the move? Indigenous temporary mobility practices in Australia', CAEPR Working Paper No. 50, CAEPR, ANU, Canberra.

Robertson, H., Lumley, J. and Berg, S. 1995. 'How midwives identify women as Aboriginal or Torres Strait Islanders', Australian College of Midwives Journal, 8 (3): 26-9.

Smith, L., Barnes, T. and Choi, C. 2008. 'Closing the gap? Monitoring trends in Indigenous Australian's life expectancy', Paper presented to the Australian Population Association 14th Biennial Conference 2008, Alice Springs.

Swanson, D. A. and Siegel, J. S. 2004. 'Introduction', in J. S. Siegel and D. A. Swanson (eds), The Methods and Materials of Demography. Second Edition, Elsevier Academic Press, San Diego.

Taylor, J. 2009. 'Indigenous demography and public policy in Australia: Population or peoples?', Journal of Population Research, 26 (2): 115-30.

- Brown, D. and Bell, M. 2006. Population Dynamics and Demographic Accounting in Arid and Savanna Australia: Methods, Issues and Outcomes, DKCRC Research Report, Desert Knowledge CRC, Alice Springs.

Zhao, Y., Guthridge, S., Li, S. and Connors, C. 2009. 'Patterns of mortality in Indigenous adults in the the Northern Territory, 1998-2003', (Letter to the Editor), Medical Journal of Australia, 191: 581-82. 